\title{
Anxiety And Depression in Chronic Kidney Disease (CKD) Patients in The Initial Phase of Hemodialysis Therapy
}

\author{
Sri Suparti", Jebul Suroso, Dhimas Anggit Prasetyo \\ Health Sciences Faculty, Universitas Muhammadiyah Purwokerto, Jalan KH. Ahmad Dahlan, 53182, Banyumas, Indonesia \\ *Corresponding author: srisuparti@ump.ac.id
}

Article history: Received: 11 January 2020 Received in revised form: 28 June 2020 Accepted: 10 May 2021 Published online: 09 August 2021

\begin{abstract}
Anxiety and depression are psychological conditions that hemodialysis patients often suffer. Unresolved anxiety can cause depression. The research aims to determine the description of anxiety and depression in chronic renal disease (CKD) patients who undergo hemodialysis (HD) therapy in the initial phase. The study was a quantitative descriptive with a survey approach involving 43 HD patients for less than eight months. The research instrument implemented was the Hospital Anxiety and Depression Scale (HADS) questionnaire. The data were analyzed using descriptive analysis by presenting frequency and category distributions. The results discovered that $29(62.8 \%)$ respondents suffered from anxiety; mild (32.6\%), moderate (25.6\%), and severe category (4.7\%). Furthermore, 16 respondents (37.2\%) experience depression; mild (20.9\%), moderate (40.0.6\%), and severe (2.3\%) categories. Anxiety and depression are common symptoms among male and female respondents with direct vascular access, respondents with two times per week HD in the first two months of HD process, adult, pre and elderly and aoccupied respondents. Screenings are carried out routinely to detect anxiety and depression as early as possible and to provide interventions according to the needs of patients through nursing care approaches.
\end{abstract}

Keywords: Anxiety, Depression, Hemodialysis, Chronic Renal Disease, HADS

C2021 Penerbit UTM Press. All rights reserved

\subsection{INTRODUCTION}

Anxiety and depression are patients' common psychological conditions that undergo hemodialysis therapy, and it is associated with high mortality, morbidity, and hospitalization (Kojima, 2012). The prevalence of anxiety and depression in hemodialysis patients is $20-40 \%$. The results of previous studies report the prevalence of anxiety is 27\% (Cukor et al., 2007), 47.8\% (Vasilopoulou et al., 2016), 41.7\% (Najafi et al., 2016), 34\% (El Filali et al., 2017), 22\% (Schouten et al., 2019), and 29\% depression (Cukor et al., 2007), 38.2\% (Vasilopoulou et al., 2016), 31\% (Najafi et al., 2016), 2016), 52, 2\% (El Filali et al., 2017), 44.5\% (Suparti dkk, 2018), 42\% symptoms of depression (Schouten et al., 2019).

The research results by Cwiek et al., (2017) mentioned that anxiety and depression were problems often faced by hemodialysis patients and influenced by marital status, low education, unemployment, and low income. Women significantly experience anxiety and depression more often. The most common depression in dialysis patients is anhedonia (loss of interest), feelings of sadness, feelings of worthlessness, guilt, hopelessness, sleep disturbance followed by decreased appetite, and decreased level of sexuality (Saraha et al., 2013).

Patients diagnosed with chronic renal failure and receiving hemodialysis experience physical and psychological effects. The results of Sopha, R.F., \& Wardhani, (2016) find a state of stress and a high level of anxiety in patients when he is determined to undergo hemodialysis therapy. It is related to the patient's characteristics (age, sex, marital status, and work status) and chronic kidney disease. Anxiety and depression also occur in pre-dialysis patients, CKD and End Stage Renal Disease (ESRD). Patients with ESRD have a higher frequency of depression compared to CKD and pre-dialysis patients (Shafi \& Shafi, 2017). Changing the pre-dialysis condition to renal replacement therapy (RRT) is a tense moment in the course of the final stages of CKD. Deciding to go through dialysis is complex and challenging. This condition can cause susceptible patients to experience anxiety, mood disorders or even worsen existing psychological problems(Turkistani et al., 2014). Depression, anxiety, and stress experienced by end-stage CKD patients are not related to the choice of peritoneal dialysis or hemodialysis. However, the exact cause of anxiety in the initial phase of dialysis is still unknown (Bezerra et al., 2018). So far, a number of research types have focused on anxiety and depression in patients, and only a few have looked specifically at the initial phase of undergoing hemodialysis therapy. The urgency of this research is to know the description of anxiety and depression in the initial phase of the first eight months undergoing hemodialysis. Therefore, it can make guidelines for providing comprehensive nursing care to reduce anxiety and minimize the incidence of depression. 


\subsection{METHODOLOGY}

This study was a quantitative descriptive with a survey approach involving 43 patients who undergo HD for less than eight months. An accidental sampling technique was implemented to obtain the sample. The research instrument used was the Hospital Anxiety and Depression Scale (HADS) questionnaire. The HADS instrument showed 14 items questions which evaluated depression, anxiety, and severity. A score of $\geq 9$ establishes a diagnosis of anxiety and depression (Rudy, 2015) and divide into 4 criteria normal, mild, moderate and severe (Mackenzie et al., 2014). The study was conducted in Purwokerto and the research inclusion criteria were the patients undergoing hemodialysis therapy $\leq 8$ months, willing to be respondents, and being able to read, write, and communicate verbally and nonverbally. The research exclusion criteria are the traveling hemodialysis, emergency patients, and incomplete documents. The research in March 2018 in the Hemodialysis Unit of Prof. Hospital dr. Margono Soekarjo. The ethics was obtained from the Ethics Commission of the Margono Soekarjo Purwokerto Hospital with number No.420/025279/III/2018. After the letter of approval from ethics was obtained, the research data of patients' information with suitable criteria were collected. Moreover, prior to the patients' hemodialysis process, the objective of the research was explained to them in order to make them understand and sign the form of informed consent. The questionnaire of the research was then distributed to the respondents completed with the guidance of the researcher. The data were analyzed using a descriptive analysis with display of frequency and category distribution.

\subsection{RESULTS}

Table 1 illustrated that the patients' characteristics as follow; female were female (58.1\%), were 16-25 years old (42.2\%), low level education (67.4\%), married (93.3\%), hemodialysis less than 4 months (60.5\%), vascular access (51.2\%) and employed (58.1\%). Furthermore, the table presented that in the early phase of hemodialysis, the patient experienced mild and moderate symptoms of anxiety and depression, and there were only 1-2 patients (out of 43) with severe level.

Table 1 Characteristics, crosstab anxiety, and depression of hemodialysis patients

\begin{tabular}{|c|c|c|c|c|c|c|c|c|c|c|}
\hline \multirow[t]{2}{*}{ Characteristic } & & \multirow[t]{2}{*}{ Frequency $(\mathbf{n})$} & \multicolumn{4}{|c|}{ Anxiety } & \multicolumn{4}{|c|}{ Depression } \\
\hline & & & Normal & Mild & Moderate & Severe & Normal & Mild & Moderate & Severe \\
\hline \multicolumn{11}{|l|}{ Sex } \\
\hline Female & & 25 & 17 & 6 & 2 & 0 & 7 & 10 & 5 & 1 \\
\hline Male & & 18 & 10 & 3 & 4 & 1 & 9 & 4 & 6 & 1 \\
\hline \multicolumn{11}{|l|}{ Age } \\
\hline Adolescents & & 19 & 3 & 0 & 0 & 0 & 3 & 0 & 0 & 0 \\
\hline Adult & & 16 & 4 & 5 & 1 & 0 & 9 & 0 & 1 & 0 \\
\hline Pre and Elde & & 10 & 9 & 9 & 9 & 2 & 15 & 9 & 5 & 0 \\
\hline \multicolumn{11}{|c|}{ Education } \\
\hline Low & Level & & & 8 & 10 & 2 & 13 & 7 & 5 & 1 \\
\hline Education & & 29 & 6 & 6 & 1 & 0 & 14 & 2 & 1 & 0 \\
\hline High & Level & 14 & 10 & & & & & & & \\
\hline \multicolumn{11}{|l|}{ Education } \\
\hline \multicolumn{11}{|l|}{ Marital Status } \\
\hline Unmarried & & 3 & 3 & 0 & 0 & 0 & 3 & 0 & 0 & 1 \\
\hline Married & & 40 & 13 & 14 & 11 & 2 & 24 & 9 & 6 & 0 \\
\hline \multicolumn{11}{|l|}{ Length of HD } \\
\hline$\leq 4$ months & & 26 & 6 & 9 & 9 & 2 & 13 & 6 & 6 & 1 \\
\hline$>4$ months & & 17 & 10 & 5 & 2 & 0 & 14 & 3 & 0 & 0 \\
\hline \multicolumn{11}{|c|}{ Access of hemodialysis } \\
\hline Vascular & & & & 6 & 9 & 2 & 10 & 6 & 5 & 1 \\
\hline AV shunt & & 22 & 5 & 8 & 2 & 0 & 16 & 11 & 1 & 0 \\
\hline Double & lumen & 20 & $\begin{array}{c}10 \\
1\end{array}$ & 0 & 0 & 0 & 1 & 0 & 0 & 0 \\
\hline catheter & & & & & & & & & & \\
\hline \multicolumn{11}{|l|}{ Occupation } \\
\hline Not occupied & & 18 & 6 & 5 & 6 & 1 & 10 & 3 & 4 & 1 \\
\hline Occupied & & 25 & 10 & 9 & 5 & 1 & 17 & 6 & 2 & 0 \\
\hline
\end{tabular}

The results show there are 29 respondents experiencing anxiety $(62.8 \%)$, with mild $(32.6 \%)$, moderate $(25.6 \%)$, and severe (4.7\%) categories. Moreover, there are 16 respondents experiencing depression (37.2\%) with mild (20.9\%), moderate (40.0.6\%), and severe categories $(2.3 \%)$ (table 2 ).

Table 2 Level of anxiety and depression of the patients in the initial phase of hemodialysis

\begin{tabular}{lcccc}
\hline Category & \multicolumn{2}{c}{ Depression } & \multicolumn{2}{c}{ Anxiety } \\
& Frequency(n) & Percentage (\%) & Frequency(n) & Percentage (\%) \\
\hline Normal & 16 & $(37.2)$ & 27 & 62.8 \\
Mild & 14 & $(32.6)$ & 9 & 20.9 \\
Moderate & 11 & $(25.6)$ & 6 & 14.0 \\
Severe & 2 & $(4.7)$ & 1 & 2.3 \\
\hline
\end{tabular}




\subsection{DISCUSSION}

The results reveal that both male and female respondents experience anxiety, but men are in higher extent. Meanwhile, the depression is experienced by a number of female respondents. These results are supported by some previous research stating that men are more stressed and anxious compared to women. Seeing the differences of culture in Indonesia, men take important roles in daily life such as the obligation to meet economic needs, to provide a sense of security, and to make decisions. The determination to get HD therapy can be a stressor for men. Men consider that HD therapy bothers their obligations, (Sopha, R.F., \& Wardhani, 2016). There is a significant correlation between the intensity of depressive symptoms and disease acceptance $(r=0.5 ; p<0.001)$. Poor mood in patients undergoing hemodialysis is associated with an increased maladaptive attitude towards chronic kidney disease. This research also confirms that there is a very high depressive disorder associated with dialysis patients (Kokoszka et al., 2016).

Most respondents experiencing anxiety and depression have direct vascular venous access and are married. Even 3 respondents with unmarried status do not experience anxiety and depression. The presence of comorbidities, loss of vascular access, and poor quality of life are associated with anxiety symptoms among dialysis patients. Depression and anxiety are common conditions of patients who experience dehydration syndrome in dialysis patients rather than transplant patients, (de Brito et al., 2019). The respondents with no Arterio fistula shunt installed experience anxiety, considering that every HD process must be carried out by injection. Moreover, respondents feel scared if the HD does not run well and bleeding occurs.

Anxiety and depression symptom are experienced by HD patients twice a week, in the first two months until four months in adulthood, pre and elderly respondents, low education respondents and employed respondents (Table 1). CKD and HD are even rising to negative emotional experience called stressors. Properly treated stressors makes individuals grow more mature, and improper treatment will trigger psychological responses such as anxiety, depression, anger, fear, guilt, and even death (DeLaune, S.C., \& Ladner, 2011). Anxiety and depression symptom often occur in the initial phase, as proven by the research findings that it happen in the first 1 to 4 months, and patients begin to adapt in the 6th month. Patients who have undergone long process of hemodialysis show less anxiety and depression (de Brito et al., 2019). Anxiety experienced by employed respondents is due to concerns of being unproductive and being fired from work. The occurrence of depression in chronic disease patients is the result of complex multifactorial interactions. These factors include the patient's personality, coping mechanisms, the presence or absence of social support, and genetic or biological predispositions. The high incidence of depression and anxiety in pre-dialysis patients is a contribution of the patient's role in the family, workplace factors, loss of physical activity, hospital visits, psychological stress, sexual dysfunction, and dialysis treatments that will be undertaken soon (Bulantekin \& Demir, 2011; Cantekin et al., 2014). The pre dialysis and dialysis patients in the initial phase experience high anxiety and depression, which results in a decrease in quality of life, even psychopathological problems, anxiety and depression which increase along with age (Hedayati et al., 2012; Lee et al., 2013).

In the final phase, anxiety symptoms are independently associated with an increased risk of death and one-year hospitalization. Anxiety symptoms are clinically relevant risk anxiety of pre-dialysis patients and provide the support needed to overcome anxiety and depression, so that the quality of life of patients can improve (Cantekin et al., 2014). The limitation of this research includes the description of anxiety and depression only in the early phase of hemodialysis with survey method and instruments of questionnaire and the small number of respondents only from one hospital. To claim that anxiety and depression are considered as disorders, further investigation is required. There needs to be a collaborative research among nurses, doctors, and psychologists to do screening as well as diagnosing the anxiety and depression with quantitative approach and mix method involving more respondents from more hospitals.

\subsection{CONCLUSION}

Anxiety and depression are the main problems in the initial phase of therapy especially in the first two months and last for up to 4 months in the respondents with vascular access, adult respondents, pre and elderly respondents, employed and low education respondents. Anxiety and depression screening is carried out routinely to be detected as early as possible and to provide interventions according to the needs of patients through nursing care approaches.

\section{References}

Bezerra, C.I.L., Silva, B.C., \& Elias, R.M. (2018). Decision-making Process In The Pre-Dialysis CKD Patients: Do Anxiety, Stress and Depression Matter? BMC Nephrology, 19, 98. https://doi.org/10.1186/s12882-018-0896-3

Bulantekin, O., \& Demir, S. (2011). Evaluation of The Quality of Life, Anxiety and Depression with Predialysis Patients. TAF Preventive Medicine Bulletin. 34(1), 69. https://doi.org/10.5455/pmb.20110523051131

Cantekin, I., Curcani, M., \& Tan, M. (2014). Determining the Anxiety and Depression Levels Of Pre-Dialysis Patients In Eastern Turkey. Renal Failure, 36(5), 678681 https://doi.org/10.3109/0886022X.2014.890009

Cukor, D., Coplan, J., Brown, C., Friedman, S., Cromwell-Smith, A., Peterson, R. A., \& Kimmel, P. L. (2007). Depression and Anxiety in Urban Hemodialysis Patients. Clinical Journal of the American Society of Nephrology, 2(3) 484-490. https://doi.org/10.2215/CJN.00040107

Cwiek, A., Czok, M., Kurczab, B., Kramarczyk, K., Drzyzga, K., \& Kucia, K. (2017). Association between Depression and Hemodialysis In Patients With Chronic Kidney Disease. Psychiatria Danubina.

de Brito, D. C. S., Machado, E. L., Reis, I. A., de Freitas do Carmo, L. P., \& Cherchiglia, M. L. (2019). Depression and Anxiety Among Patients Undergoing Dialysis and Kidney Transplantation: A Cross-Sectional Study. Sao Paulo Medical Journal, 137(2):137-47. https://doi.org/10.1590/1516-3180.2018.0272280119

DeLaune, S.C., \& Ladner, P. K. (2011). Fundamentals of Nursing: Standards and Practice (4th Ed.). Cengage Learning: United States.

El Filali, A., Bentata, Y., Ada, N., \& Oneib, B. (2017). Depression and Anxiety Disorders in Chronic Hemodialysis Patients And Their Quality Of Life: A CrossSectional Study About 106 Cases In The Northeast Of Morocco. Saudi Journal of Kidney Diseases and Transplantation : An Official Publication of the Saudi Center for Organ Transplantation, 28(2), 341-348. https://doi.org/10.4103/1319-2442.202785 Saudi Arabia

Hedayati, S. S., Yalamanchili, V., \& Finkelstein, F. O. (2012). A Practical Approach to The Treatment of Depression in Patients With Chronic Kidney Disease and End-Stage Renal Disease. In Kidney International, 81(3), 247-255. https://doi.org/10.1038/ki.2011.358

Kojima, M. (2012). Epidemiologic studies of psychosocial factors associated 
Kokoszka, A., Leszczyńska, K., Radzio, R., Daniewska, D., Łukasiewicz, A., Orzechowski, W. M., Piskorz, A., \& Gellert, R. (2016). Prevalence of depressive and anxiety disorders in dialysis patients with chronic kidney disease. Archives of Psychiatry and Psychotherapy, 1, 8-13. https://doi.org/10.12740/APP/61977

Lee, Y. J., Kim, M. S., Cho, S., \& Kim, S. R. (2013). Association of depression and anxiety with reduced quality of life in patients with predialysis chronic kidney disease. International Journal of Clinical Practice, 67(4), 363-368. https://doi.org/10.1111/ijcp.12020 Mackenzie, L.J., Carey, M.L., Sanson-fisher, R.W., D'este, C.A., Paul, C.L., \& Yoong, S.L. (2014). Agreement between Hads Classifications and Single-Item Screening Questions for Anxiety and Depression: A Cross-Sectional Survey of Cancer Patients. Annals of Oncology, 25(4), 889-895. https://doi.org/10.1093/annonc/mdu023

Najafi, A., Keihani, S., Bagheri, N., Jolfaei, A. G., \& Meybodi, A. M. (2016). Association between Anxiety and Depression with Dialysis Adequacy in Patients on Maintenance Hemodialysis. Iranian Journal of Psychiatry and Behavioral Sciences, 10(2): 4962. https://doi.org/10.17795/ijpbs-4962

Rudy, et al. (2015). Reliability Indonesian Version of the Hospital Anxiety and Depression Scale (HADS) of Stroke Patients in Sanglah General Hospital Denpasar. Research Gatee. Faculty of Medicine, Udayana University.

Saraha, S., Kanine, E., \& Wowiling, F. (2013). Hubungan Dukungan Keluarga Dengan Depresi Pada Pasien Penyakit Ginjal Kronik Di Ruangan Hemodialisa Blu Rsup Prof. Dr. R D. Kandou Manado. Jurnal Keperawatan UNSRAT, 1(1), 7-13.

Schouten, R.W., Haverkamp, G.L., Loosman, W.L., Chandie Shaw, P.K., van Ittersum, F.J., Smets, Y.F.C., Vleming, L.J., Dekker, F.W., Honig, A., \& Siegert, C.E.H (2019). Anxiety Symptoms, Mortality, and Hospitalization in Patients Receiving Maintenance Dialysis: A Cohort Study. American Journal of Kidney Diseases, 74(2), 158-166. https://doi.org/10.1053/j.ajkd.2019.02.017

Shafi, S.T., \& Shafi, T. (2017). A Comparison of Anxiety and Depression between Pre-Dialysis Chronic Kidney Disease Patients and Hemodialysis Patients Using Hospital Anxiety and Depression Scale. Pakistan Journal of Medical Sciences, 33(4):876-880. https://doi.org/10.12669/pjms.334.12656

Sopha, R.F., \& Wardhani, I. (2016). Stres dan Tingkat Kecemasan Saat Ditetapkan Perlu Hemodialisis Berhubungan Dengan Karakteristik Pasien. Jurnal Keperawatan Indonesia, 19(1), 55-61.

Suparti dkk, S. (2018). Hubungan Depresi dengan Fatigue pada Pasien Hemodialisis. Journal of Health Studies. 2(1), 63-75. https://doi.org/10.31101/jhes.435

Turkistani, I., Nuqali, A., Badawi, M., Taibah, O., Alserihy, O., Morad, M., \& Kalantan, E. (2014). The Prevalence Of Anxiety And Depression Among End-Stage Renal Disease Patients On Hemodialysis in Saudi Arabia. Renal Failure, 36(10), 1510-1515. https://doi.org/10.3109/0886022X.2014.949761

Vasilopoulou, C., Bourtsi, E., Giaple, S., Koutelekos, I., Theofilou, P., \& Polikandrioti, M. (2016). The Impact of Anxiety and Depression on the Quality of Life of Hemodialysis Patients. Global Journal of Health Science, 8(1), 45-55. https://doi.org/10.5539/gjhs.v8n1p45 